\title{
Ocorrência de plantas tóxicas em escolas do município de Timbiras/MA, Brasil
}

As plantas são fundamentais para a manutenção da vida, pois nos fornecem oxigênio, alimentos e contribuem para a produção de fármacos. Algumas plantas são consideradas tóxicas e podem causar envenenamentos em seres humanos e animais. Essas plantas possuem substâncias químicas que podem causar intoxicações quando ingeridas ou em contato com partes do animal. A maioria dos casos de intoxicação são acidentais e outros acontecem quando o indivíduo ingere continuada e propositalmente certas espécies vegetais. Tendo em vista que as crianças são as principais vítimas de acidentes por plantas tóxicas e que essas plantas podem ser encontradas em ambientes públicos como praças e ambientes escolares, esta pesquisa objetivou inventariar a ocorrência de plantas tóxicas em 17 escolas do município de Timbiras, MA, Brasil e investigar o conhecimento da comunidade escolar. A pesquisa se deu por meio da coleta de informações sobre as espécies e da aplicação de questionários. Foi constatado a presença de plantas tóxicas em $70 \%$ das escolas, apresentando, portanto, riscos de acidente por plantas. Foram levantadas 16 espécies de plantas tóxicas distribuídas em nove famílias. As espécies mais ocorrentes foram Jatropha gossypiifolia L. (pinhão-roxo), Caladium bicolor (Aiton) Vent. (tinhorão), Catharanthus roseus (L.) (vinca), Dieffenbachia seguine (Jacq) Schott. (comigo-ninguém-pode), e Ricinus communis (L.) (mamona) e as famílias botânicas mais frequentes foram Euphorbiaceae, Apocynaceae e Araceae. Esses resultados reforçam a necessidade de difundir o conhecimento sobre plantas tóxicas dentro dos espaços escolares, afim de evitar possíveis acidentes envolvendo crianças e esses vegetais.

Palavras-chave: Acidentes por plantas; Intoxicação; Toxicidade de plantas.

\section{Occurence of toxic plant at schools of the city Timbiras/MA, Brazil}

Plants are fundamental for the existence of life of many other organisms, they provide us oxygen and a variety of food supply and contribute to the production of pharmaceutical medicines. Some plants are considered toxic and can poison humans and other animals. These plants have chemical compounds that may cause intoxications when ingested or when they get in contact with parts of the animal. Intoxication in most cases are accidental and others happen when individuals ingest its toxic compounds, intentionally and continuously. Considering that children are the principal victims of these accidents caused by toxic plants and them can be easily found in public environments like parks and schools, this research aimed to make an inventory of incidents caused by toxic plants in 17 schools of the city Timbiras, MA in Brazil, and to investigate the school community knowledge about this threat. In this research, we investigated the information about the species incidence and we applied questionnaires. The presence of toxic plants was identified in $70 \%$ of the schools, thus presenting accident risks for children. Sixteen species of toxic plants were found, classified in nine families. The most frequent species were Jatropha gossypiifolia L. (pinhão-roxo), Caladium bicolor (Aiton) Vent. (tinhorão), Catharanthus roseus (L.) (vinca), Dieffenbachia seguine (Jacq) Schott. (comigo-ninguém-pode), e Ricinus communis (L.) (mamona) furthermore the most frequent botanical families were Euphorbiaceae, Apocynaceae, and Araceae.

Keywords: Accidents for plants; Intoxication; Plants toxicity.

Topic: Planejamento, Gestão e Políticas Públicas Ambientais

Reviewed anonymously in the process of blind peer.
Received: 20/11/2019

Approved: 24/02/2020
Ednilson Barros Barroso (iD

Universidade Federal de Lavras, Brasil

http://lattes.cnpq.br/3447224585476878

http://orcid.org/0000-0003-2137-5330

e barr03@live.de

Eduardo Oliveira Silva (it)

Universidade Federal do Maranhão, Brasil http://lattes.cnpq.br/5517282422965192

http://orcid.org/0000-0002-8899-2774

eoliveira12@yahoo.com.br

Rayane Frazão Olanda (iD

Universidade Federal do Maranhão, Brasil http://lattes.cnpq.br/6004981898550182 http://orcid.org/0000-0003-2825-1170 rayane frazao@hotmail.com

\section{Referencing this:}

BARROSO, E. B.; SILVA, E. O.; OLANDA, R. F.. Ocorrência de plantas tóxicas em escolas do município de Timbiras/MA, Brasil. Natural Resources, v.10, n.1, p.27-39, 2020. DOI: http://doi.org/10.6008/CBPC2237-9290.2020.001.0004 


\section{INTRODUÇÃO}

As plantas são seres vivos fundamentais na natureza e indispensáveis para a nossa sobrevivência na terra, pois nos fornecem oxigênio e alimento por meio do processo de fotossíntese. Elas são a base da cadeia alimentar e estão presentes não só na nossa alimentação, mas em diversas outras necessidades do ser humano. $O$ interesse pelas plantas cresce anualmente no Brasil e no mundo, devido ao potencial farmacêutico e toxicológico dessas espécies. Entre os vegetais, as plantas medicinais (CAMPIOTO et al., 2012), constituem um grupo importante, dado seu potencial etnobotânico e econômico (TEIXEIRA, 2011). Também, os estudos com plantas tóxicas, apresentam interesse de saúde pública e econômica pois estão voltados aos casos de intoxicações acidentais nos seres humanos e animais (CAMPIOTO et al., 2012).

Planta tóxica, como todo vegetal, possui substâncias com propriedades naturais, físicas, químicas ou físico-químicas que, quando introduzidas no organismo de animais ou humanos, pode causar problemas de saúde nesses seres, provocando reações biológicas diversas, conhecidas como sintomas de intoxicação (HARAGUCHI, 2003). No entanto, apenas o fato dessas plantas possuírem essas substâncias químicas não é o suficiente para classificá-la como tóxica. Os requisitos principais da possível toxicidade de uma planta é o relato de casos de pessoas ou observação de animais que tenham desenvolvido um quadro clínico após ingerir ou entrar em contato com a espécie (OLIVEIRA et al., 2003).

Essas plantas tóxicas comumente possuem flores coloridas e bem atrativas, o que atrai olhares e toques de pessoas que as desconhecem, podendo ser um grande risco para quem a manuseiam. Inúmeras dessas espécies são encontradas em jardins e, portanto, são nocivas, principalmente às crianças, que podem ser vítimas de intoxicações (ALBUQUERQUE, 1980). Ocasionalmente, os casos de intoxicações por plantas podem levar a consequências sérias, pondo em risco a vida dos pacientes. Contudo, nem todas as plantas consideradas tóxicas causam graves envenenamentos. Na maioria dos casos, esses acidentes provocam apenas náuseas, vômitos e diarreia. São raros os casos que levam a problemas mais sérios como desordens neurológicas, cardíacas, coma ou morte. Entretanto, é de suma importância as medidas preventivas com o intuito de reduzir cada vez mais a frequência e a severidade das intoxicações causadas por esses vegetais (OLIVEIRA et al., 2003).

O grau de toxidade depende da quantidade de substância que o indivíduo absorve, da natureza da substância e da via de introdução (HARAGUCHI, 2003). Esse grau de toxicidade das plantas vai depender de alguns fatores, como: a) parte do vegetal ingerida; b) a idade da planta e o grau de amadurecimento do fruto; c) a taxa de sensibilização do indivíduo aos compostos do vegetal ingerido, e d) a quantidade ingerida e a maneira da ingestão (OLIVEIRA et al., 1997, citado por SANTOS et al., 2012).

A intoxicação pode ser aguda, quando há o contato ou ingestão da parte da planta que contenha o componente tóxico capaz de provocar manifestações graves num curto período de tempo, ou crônica, quando o indivíduo ingere continuada, proposital ou acidentalmente certas espécies de vegetais. Esta pode ocorrer também por manifestações cutâneas, quando há o contato sistemático com vegetais (HARAGUCHI, 2003; TEIXEIRA et al., 2011). 
Com base nos dados do Sistema Nacional de Informações Tóxico - Farmacológicas (SINITOX 2019), dos casos registrados de intoxicação humana por plantas no Brasil nos últimos cinco anos, 60 a $70 \%$ ocorrem entre a faixa etária de zero a 14 anos, sendo as crianças de 1 a 4 anos as principais vítimas. Conforme Vasconcelos et al. (2009) a maioria dos acidentes ocorrem com plantas cultivadas em vasos dentro das próprias residências. Braga et al. (2017) afirmam que a ocorrência de intoxicação por plantas deve-se ao fato de que as crianças são atraídas pelas cores das folhas, flores e frutos, o que instiga a sua curiosidade e o desejo de manter o contato com esses vegetais, embora não conheçam ainda o perigo à saúde.

Os casos mais frequentes de intoxicações em crianças são devidos também as brincadeiras com partes das plantas (BOCHNER et al., 2013). É algo típico das crianças menores colocar na boca tudo o que elas encontram. Esse é o seu modo de investigar e entender o mundo. As crianças maiores podem comer algumas frutas coloridas por curiosidade ou pelo fato de desconhecer, sem saber dos riscos (HESSE, 1998). Para Teixeira (2011), as crianças com idades entre zero e cinco anos intoxicam-se, geralmente, com plantas ornamentais cultivadas nas residências. Dentre elas, estão as plantas: comigo-ninguém-pode, o antúrio e o tinhorão. Nas células das folhas e dos caules dessas plantas há cristais de oxalato de cálcio na forma de agulhas que perfuram a boca da criança quando são ingeridas por elas. Em crianças de seis a 12 anos, os casos de intoxicação ocorrem geralmente com a coroa-de-cristo, o pinhão-branco, o pinhão-roxo, a mamona e o chapéu-de-napoleão. Em adultos, as intoxicações também são frequentes, causadas principalmente pelo uso inadequado de plantas medicinais, alucinógenas e abortivas. Dentre as plantas que mais causam intoxicações nos adultos estão a buchinha e a saia-branca.

As plantas tóxicas são facilmente encontradas em ambientes públicos como canteiros, praças, em pátios de escolas e creches (VASCONCELOS et al., 2009). Essas plantas, por serem bastante conhecidas e apreciadas, e geralmente de fácil acesso, apresentam risco, principalmente em crianças. E com o aumento do número de casos de intoxicação por alimentos, automedicações, produtos químicos, animais peçonhentos e plantas tóxicas, percebe-se a importância de ações como o conhecimento e a divulgação das possíveis medidas de proteção como forma de prevenção (FOOK et al., 2014). Diante disso, esta pesquisa objetivou inventariar as espécies de plantas tóxicas presentes nos ambientes escolares do município de Timbiras, Maranhão; realizar um levantamento de casos de intoxicação nas escolas do município; avaliar os riscos e exposição das crianças à essas plantas, e o conhecimento da comunidade escolar sobre o assunto.

\section{METODOLOGIA}

O Município de Timbiras, localiza-se na microrregião de Codó, mesorregião do Leste Maranhense, entre as coordenadas $4^{\circ} 15^{\prime} 18^{\prime \prime}$ LS e $43^{\circ} 56^{\prime} 27^{\prime \prime}$ LW. Com uma área de $1.486 \mathrm{~km}^{2}$ situa-se à margem direita do rio Itapecuru, a 316 quilômetros da capital São Luís. O clima predominante é o tropical, caracterizado por um período chuvoso de dezembro a maio, com níveis pluviométricos mais acentuados entre janeiro e abril. A temperatura média é de 27 graus Celsius. A vegetação predominante da região é típica do Cerrado, com mata de cocais, com incidência quase absoluta da palmeira de babaçu (Attalea speciosa Mart. ex Spreng.), além de matas de galeria (MARANHÃO, 2011). 
Com base no Censo Escolar (2018), há no município 56 escolas de ensino infantil e fundamental, com um total de 9.240 estudantes matriculados e duas escolas de ensino médio, com 1.018 estudantes matriculados, distribuídas na zona rural e urbana.

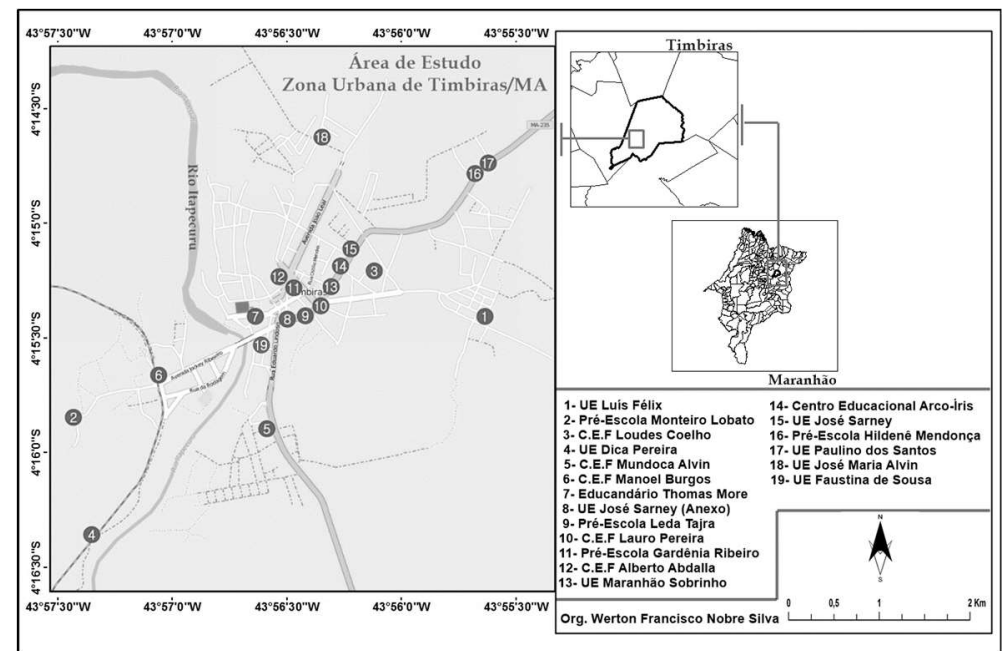

Figura 1: Escolas Municipais públicas e privadas de ensino primário e fundamental.

A área de estudo desta pesquisa foi limitada apenas às escolas da zona urbana de Timbiras/MA, sendo que duas delas, Educandário Thomas More e Centro Educacional Arco-Íris, não foram inseridas, devido à ausência de plantas consideradas tóxicas (Figura 1). A pesquisa constituiu-se de uma ampla coleta de informações sobre as espécies vegetais tóxicas ocorrentes em 17 escolas da zona urbana, sendo quatro préescolas, oito unidades de ensino e cinco centros de ensino fundamental, nas quais estão os alunos de três a cinco anos, seis a dez anos e 11 a 14 anos, respectivamente (Tabela 1 ).

Tabela 1: Escolas urbanas de ensino primário e fundamental do Município de Timbiras/MA.

\begin{tabular}{|l|l|l|}
\hline QTD. & NOME DA INSTITUIÇÃO & SIGLA \\
\hline 01 & CEF Alberto Abdalla & C1 \\
\hline 02 & CEF Lauro Pereira & C2 \\
\hline 03 & CEF Lourdes Coelho & C3 \\
\hline 04 & CEF Manoel Burgos & C4 \\
\hline 05 & CEF Mundoca Alvim & C5 \\
\hline 06 & Pré-Escola Gardênia Ribeiro & P1 \\
\hline 07 & Pré-Escola Hildenê Mendonça & P2 \\
\hline 08 & Pré-Escola Leda Tajra & P3 \\
\hline 09 & Pré-Escola Monteiro Lobato & P4 \\
\hline 10 & UE Dica Pereira & U1 \\
\hline 11 & UE Faustina de Sousa & U2 \\
\hline 12 & UE José Maria Alvim & U3 \\
\hline 13 & UE José Sarney & U4 \\
\hline 14 & UE José Sarney (Anexo) & U5 \\
\hline 15 & UE Luís Félix & U6 \\
\hline 16 & UE Maranhão Sobrinho & U7 \\
\hline 17 & UE Paulino dos Santos & U8 \\
\hline
\end{tabular}

Inicialmente, foi solicitado aos gestores das escolas, através de ofício, a permissão para a realização da pesquisa. Em seguida, foram feitas visitas para a coleta das informações, na qual as espécies vegetais ornamentais e daninhas presentes nos canteiros e proximidades da escola, de fácil acesso aos alunos, foram listadas e fotografadas. Anotou-se as observações peculiares de cada planta e dados referentes à 
nomenclatura vulgar, informado por membros da comunidade escolar. A identificação, por sua vez, foi realizada através de metodologia usual taxonômica, com uso de bibliografia especializada e colaboração de taxonomistas.

Para revisão dos nomes científicos das espécies citadas, foram utilizados os bancos de dados da Flora do Brasil 2020, The Plant List e Trópicos. As espécies foram classificadas de acordo com o sistema APG IV. Os dados encontrados foram tabulados em planilha Excel e organizados em ordem alfabética quanto ao nome das espécies.

Com base em Mueller-Dombois et al. (1974), foi feito uma adaptação para realizar o cálculo da densidade relativa (DRi) a partir da razão entre o número de espécies ocorrentes em cada escola (Ni) e o somatório do número de espécies de todas as escolas $(N)$, resultando em dados percentuais, conforme a equação abaixo:

$$
D R i=\frac{N i .100}{N}
$$

Onde,

$D R i$ é a densidade relativa;

$N i$ é o número de espécies ocorrentes na escola $i$;

$N$ é somatório do número de espécies de todas as escolas.

Foi investigado também, o nível de conhecimento da comunidade escolar sobre a toxicidade das plantas, pela aplicação de questionários entre funcionários (professores, técnico-administrativos e direção) e alunos, à uma amostra de 140 voluntários.

\section{RESULTADOS E DISCUSSÃO}

\section{Ocorrência de plantas tóxicas nas escolas pesquisadas}

Neste estudo foi registrado a presença de 16 espécies de plantas tóxicas e observou-se a presença de pelo menos uma planta em $70 \%$ das escolas visitadas. As que apresentaram maior ocorrência foram as escolas C5, U4, C2, P3 e P4, nessa ordem. Entre as espécies identificadas nas escolas, as mais ocorrentes foram Jatropha gossypiifolia L. (14,7\%), Caladium bicolor (Aiton) Vent. (11,8\%), Catharantus roseus (L.) Don., Dieffenbachia seguine (Jacq.) Schott e Ricinus communis L., todas presentes em 8,8\% das escolas (Tabela 2).

Tabela 2: Espécies vegetais tóxicos ocorrentes nas escolas de Timbiras.

\begin{tabular}{|l|l|l|l|l|l|l|l|l|l|l|l|l|l|l|l|l|l|l|l|}
\hline $\begin{array}{l}\text { NOME CIENTíFICO } \\
\text { DAS ESPÉCIES }\end{array}$ & $\mathbf{C 1}$ & $\mathbf{C 2}$ & $\mathbf{C 3}$ & $\mathbf{C 4}$ & $\mathbf{C 5}$ & $\mathbf{P 1}$ & $\mathbf{P 2}$ & $\mathbf{P 3}$ & $\mathbf{P 4}$ & $\mathbf{U 1}$ & $\mathbf{U 2}$ & $\mathbf{U 3}$ & $\mathbf{U 4}$ & $\mathbf{U 5}$ & $\mathbf{U 6}$ & $\mathbf{U 7}$ & $\mathbf{U 8}$ & $\mathbf{N i}$ & $\begin{array}{l}\text { DRi } \\
\text { (\%) }\end{array}$ \\
\hline $\begin{array}{l}\text { Caladium bicolor } \\
\text { (Aiton) Vent. }\end{array}$ & 0 & 1 & 0 & 0 & 0 & 0 & 1 & 0 & 0 & 0 & 0 & 0 & 1 & 0 & 0 & 1 & 0 & 4 & 11.8 \\
\hline $\begin{array}{l}\text { Catharanthus roseus } \\
\text { (L.) G.Don }\end{array}$ & 0 & 0 & 0 & 0 & 0 & 0 & 1 & 1 & 0 & 0 & 0 & 0 & 1 & 0 & 0 & 0 & 0 & 3 & 8.8 \\
\hline $\begin{array}{l}\text { Codiaeum variegatum } \\
\text { (L.) Rumph. ex A. } \\
\text { Juss. }\end{array}$ & 0 & 0 & 0 & 0 & 1 & 0 & 0 & 0 & 0 & 0 & 0 & 0 & 1 & 0 & 0 & 0 & 0 & 2 & 5.9 \\
\hline $\begin{array}{l}\text { Dieffenbachia seguine } \\
\text { (Jacq.) Schott. }\end{array}$ & 0 & 0 & 0 & 0 & 1 & 1 & 0 & 0 & 0 & 1 & 0 & 0 & 0 & 0 & 0 & 0 & 0 & 3 & 8.8 \\
\hline Duranta erecta L. & 0 & 0 & 0 & 0 & 1 & 0 & 0 & 0 & 0 & 0 & 0 & 0 & 0 & 0 & 0 & 0 & 0 & 1 & 2.9 \\
\hline Ficus benjamina L. & 0 & 0 & 1 & 1 & 0 & 1 & 0 & 0 & 0 & 0 & 0 & 0 & 0 & 0 & 0 & 0 & 0 & 2 & 5.9 \\
\hline $\begin{array}{l}\text { Hymenocallis littoralis } \\
\text { (Jacq) Salisb. }\end{array}$ & 0 & 0 & 0 & 0 & 0 & 0 & 0 & 0 & 0 & 0 & 0 & 0 & 1 & 0 & 0 & 0 & 0 & 1 & 2.9 \\
\hline $\begin{array}{l}\text { Jatropha gossypiifolia } \\
\text { L. }\end{array}$ & 0 & 1 & 0 & 0 & 1 & 0 & 1 & 0 & 0 & 1 & 0 & 0 & 0 & 0 & 1 & 0 & 0 & 5 & 14.7 \\
\hline Jatropha podagrica & 0 & 0 & 0 & 0 & 1 & 0 & 0 & 0 & 0 & 0 & 0 & 0 & 0 & 0 & 0 & 0 & 0 & 1 & 2.9 \\
\hline
\end{tabular}




\begin{tabular}{|c|c|c|c|c|c|c|c|c|c|c|c|c|c|c|c|c|c|c|c|}
\hline Hook & & & & & & & & & & & & & & & & & & & \\
\hline $\begin{array}{l}\text { Manihot esculenta } \\
\text { Crantz }\end{array}$ & 0 & 0 & 0 & 0 & 0 & 1 & 0 & 0 & 0 & 0 & 0 & 0 & 0 & 0 & 0 & 0 & 0 & 1 & 2.9 \\
\hline Ricinus communis L. & 0 & 1 & 0 & 0 & 0 & 1 & 0 & 0 & 0 & 0 & 1 & 0 & 0 & 0 & 0 & 0 & 0 & 3 & 8.8 \\
\hline $\begin{array}{l}\text { Sansevieria trifasciata } \\
\text { Prain; }\end{array}$ & 0 & 0 & 1 & 0 & 0 & 0 & 0 & 0 & 0 & 0 & 0 & 0 & 1 & 0 & 0 & 0 & 0 & 2 & 5.9 \\
\hline $\begin{array}{l}\text { Tabernaemontana } \\
\text { divaricata (L.) R.Br ex } \\
\text { Roem. \& Schult. }\end{array}$ & 0 & 0 & 1 & 0 & 0 & 0 & 0 & 1 & 0 & 0 & 0 & 0 & 0 & 0 & 0 & 0 & 0 & 2 & 5.9 \\
\hline $\begin{array}{l}\text { Thevetia peruviana } \\
\text { (Pers.) K. Schum }\end{array}$ & 0 & 0 & 0 & 0 & 1 & 0 & 0 & 0 & 0 & 0 & 0 & 0 & 0 & 0 & 0 & 0 & 0 & 1 & 2.9 \\
\hline $\begin{array}{l}\text { Tithonia diversifolia } \\
\text { (Hemsl.) A. Gray }\end{array}$ & 0 & 0 & 0 & 0 & 0 & 1 & 1 & 0 & 0 & 0 & 0 & 0 & 0 & 0 & 0 & 0 & 0 & 2 & 5.9 \\
\hline Urtica dioica L. & 0 & 1 & 0 & 0 & 0 & 0 & 0 & 0 & 0 & 0 & 0 & 0 & 0 & 0 & 0 & 0 & 0 & 1 & 2.9 \\
\hline 16 espécies & 0 & 4 & 3 & 1 & 6 & 4 & 4 & 2 & 0 & 2 & 1 & 0 & 5 & 0 & 1 & 1 & 0 & 34 & 100 \\
\hline
\end{tabular}

Nas pré-escolas, a ocorrência foi significativa, uma vez que foram encontradas em $75 \%$ delas, várias plantas tóxicas, sendo tinhorão, boa-noite, comigo-niguém-pode e espada-de-são-jorge, as espécies mais ocorrentes nessas escolas (Figura 2). Essas plantas, conforme citado, são as mais atraentes para as crianças dessa faixa etária. Nas unidades de ensino, o percentual de ocorrência foi de 62,5\%. Além dessas espécies citadas acima, observou presença do pinhão-roxo e da mamona, duas espécies bastante atraídas por crianças dessa faixa etária. Nos centros de ensino, o percentual foi bem maior, chegando a $80 \%$.

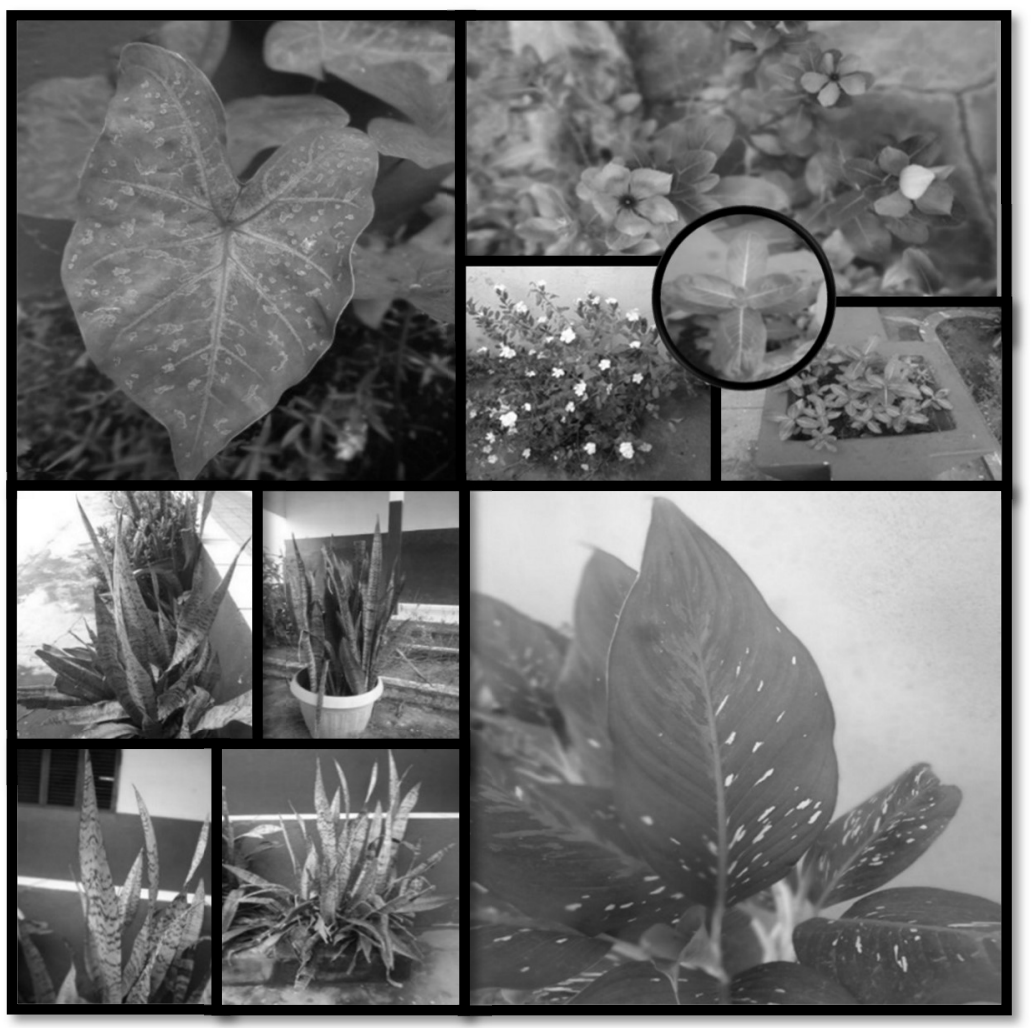

Figura 2: Plantas tóxicas mais ocorrentes nas pré-escolas. ${ }^{1}$

\footnotetext{
${ }^{1}$ A. C. bicolor, popularmente conhecida na região como pica-pau. A ingestão dessa planta ou a mastigação de partes de planta provoca irritações mucosas, edemas de lábios, boca e língua, seguidos de dor em queimação, salivação constante, vômitos, dificuldade de engolir, cólicas e náuseas e asfixia. O contato com a pele pode provocar irritação, edema e dor. Nos olhos pode ocorrer intensa irritação, edemas, fotofobia e lesão da córnea.

B. C. roseus (boa-noite). A ingestão da planta ou seiva pode provocar desordens gastrintestinais, vermelhidão na pele e queda na pressão sanguínea.

C. S. trifasciata (espada-de-são-jorge). A ingestão do vegetal provoca edema de lábios, boca, língua e palato, podendo ocorrer problemas respiratórios, queimações, salivação constante e vômitos. Em casos mais graves pode ocorrer necrose tubular renal com anúria. A pele, quando em contato com a seiva, passa a irritar juntamente com eritema, edema e dores. Nos olhos pode provocar conjuntivite, fotofobia e lacrimejamento.

D. D. seguinte (comigo-ninguém-pode). Do mesmo modo que a espécie C. bicolor, a ingestão de qualquer parte ou mesmo a mastigação da planta D. seguinte provoca rapidamente intensas manifestações de irritação de mucosas, edema de lábios, boca e língua, com queimações, salivação constante, dificuldades para engolir, cólicas, náuseas e vômitos e asfixia. O contato com os olhos é seguido por edema, fotofobia, lacrimejamento e lesões na córnea.
} 
Para Fook et al. (2014), esses resultados evidenciam sinais de alertas para os pais de alunos e responsáveis pelas escolas sobre a presença de plantas consideradas tóxicas, visto que existe o risco de intoxicação. A partir disso, percebe-se a importância da intervenção nessas escolas, com o objetivo de levar o conhecimento das espécies tóxicas, no sentido de informar, conscientizar e sensibilizar as mesmas sobre os riscos.

\section{Inventário das plantas tóxicas ocorrentes nas escolas}

As espécies vegetais tóxicas identificadas estão distribuídas em nove famílias botânicas. Com base em literaturas especializadas e no conhecimento popular da região investigada, foi feito a identificação do nome vulgar de cada espécie e também das partes das plantas definidas como tóxicas (tabela 3). Todas as espécies encontradas estavam ao alcance das crianças, dentro das escolas e nas proximidades de fácil acesso, constituindo-se uma exposição ao risco de acidente.

Tabela 3: Espécies vegetais tóxicas identificadas nas escolas do município de Timbiras.

\begin{tabular}{|c|c|c|c|}
\hline NOME POPULAR & FAMÍLIA/ESPÉCIE & PARTE TÓXICA & REFERÊNCIA \\
\hline & Amaryllidaceae & & \\
\hline \multirow[t]{2}{*}{ Lírio-aranha; lírio; aligátor } & Hymenocallis littoralis (Jacq) Salisb. & bulbos & Nelson et al. (2007) \\
\hline & Apocynaceae & & \\
\hline Vinca; boa-noite & Catharanthus roseus (L.) G. Don & Todas as partes & $\begin{array}{l}\text { Agra et al. (2007); Nelson et al. (2007); Cabral et al. } \\
\text { (2015) }\end{array}$ \\
\hline Jasmim & $\begin{array}{l}\text { Tabernaemontana divaricata (L.) } \\
\text { R.Br. ex Roem. \& Schult. }\end{array}$ & Todas as partes & Agra et al. (2007) \\
\hline \multirow[t]{2}{*}{ Chapéu-de-Napoleão } & $\begin{array}{l}\text { Thevetia peruviana (Pers.) K. } \\
\text { Schum. }\end{array}$ & Todas as partes & $\begin{array}{l}\text { Duke (1929); Oliveira et al. (2003); Nelson et al. (2007); } \\
\text { Matos et al. (2011); Bochner et al. (2013); Braga et al. } \\
\text { (2017) }\end{array}$ \\
\hline & Araceae & & \\
\hline $\begin{array}{l}\text { Tinhorão; caládio; coração- } \\
\text { de-jesus; taiá; tajá; pica-pau }\end{array}$ & Caladium bicolor (Aiton) Vent. & Todas as partes & $\begin{array}{l}\text { Duke (1929); Barg (2004); } \\
\text { Nelson et al. (2007); Campioto et al. (2012); Bochner et } \\
\text { al. (2013); Braga et al. (2017) }\end{array}$ \\
\hline \multirow[t]{2}{*}{ Comigo-ninguém-pode } & $\begin{array}{lll}\text { Dieffenbachia seguine } & \text { (Jacq.) } \\
\text { Schott }\end{array}$ & Todas as partes & $\begin{array}{l}\text { Duke (1929); Matos et al. (2011); } \\
\text { Bochner et al. (2013); Oliveira et al. (2003); Braga et al. } \\
\text { (2017) }\end{array}$ \\
\hline & Asparagaceae & & \\
\hline \multirow[t]{2}{*}{ Espada-de-São-Jorge } & Sansevieria trifasciata Prain. & Todas as partes & Bochner et al. (2013); Braga et al. (2017) \\
\hline & Asteraceae & & \\
\hline \multirow[t]{2}{*}{ Girassol-mexicano } & $\begin{array}{l}\text { Tithonia diversifolia (Hemsl.) A. } \\
\text { Gray }\end{array}$ & Folhas e flores & Passoni et al. (2013) \\
\hline & Euphorbiaceae & & \\
\hline Mosquito; cróton & $\begin{array}{l}\text { Codiaeum variegatum (L.) Rumph. } \\
\text { ex A.Juss. }\end{array}$ & Sementes & $\begin{array}{l}\text { Oliveira et al. (2003); Ogunwenmo et al. (2007); } \\
\text { Petzold (2015); Braga et al. (2017) }\end{array}$ \\
\hline Pinhão-Roxo & Jatropha gossypiifolia L. & $\begin{array}{l}\text { Sementes } \\
\text { látex }\end{array}$ & $\begin{array}{l}\text { Nelson et al. (2007); Bochner et al (2013); Braga et al. } \\
(2017)\end{array}$ \\
\hline Batata do inferno; tártago & Jatropha podagrica Hook. & Toda as partes & Stuart Junior (2016); \\
\hline $\begin{array}{l}\text { Mandioca; mandioca-brava; } \\
\text { macaxeira }\end{array}$ & Manihot esculenta Crantz & Folhas e raízes & $\begin{array}{l}\text { Haraguchi (2003); Nelson et al. (2007); Matos et al. } \\
\text { (2011); Cabral (2016) }\end{array}$ \\
\hline \multirow[t]{2}{*}{ Mamona } & Ricinus communis $\mathrm{L}$. & Sementes & $\begin{array}{l}\text { Haraguchi (2003); Oliveira, et al. (2003); Nelson et al. } \\
(2007)\end{array}$ \\
\hline & Moraceae & & \\
\hline \multirow[t]{2}{*}{ Figueira-benjamin } & Ficus benjamina $\mathrm{L}$. & Folhas e látex & $\begin{array}{l}\text { Nelson et al. (2007); Biondi et al. (2008); Lopes et al. } \\
\text { (2009); Braga et al. (2017) }\end{array}$ \\
\hline & Urticaceae & & \\
\hline \multirow[t]{2}{*}{ Urtiga; cansação, } & Urtica dioica $\mathrm{L}$. & $\begin{array}{l}\text { Pelos do caule e } \\
\text { folhas }\end{array}$ & $\begin{array}{l}\text { Nelson et al. (2007); Bochner et al. (2013); Braga et al. } \\
\text { (2017) }\end{array}$ \\
\hline & Verbenaceae & & \\
\hline Pingo-de-ouro & Duranta erecta L. & frutos & $\begin{array}{l}\text { Nelson et al. (2007); Lopes et al. (2009); Braga et al. } \\
\text { (2017) }\end{array}$ \\
\hline
\end{tabular}

Na tabela 3, é possível ver claramente que as espécies mais ocorrentes nas pré-escolas são as que proporcionam maior risco, uma vez que todas as partes dessas plantas são tóxicas. Pode-se perceber que as 
escolas não atribuem critérios para a escolha das plantas ornamentais, assim como há um descaso em relação aos cuidados com plantas que não são consideradas ornamentais, como o pinhão-roxo, a mamona, urtiga, mandioca.

Para Braga et al. (2017), é imprescindível o conhecimento sobre plantas tóxicas, pois muitos dos casos de intoxicação é devido às inadequadas escolhas e uso desses vegetais na ornamentação de locais públicos como escolas, praças, ruas e shoppings. Os autores afirmam ainda que, deve haver uma preocupação por parte do gestor escolar em realizar estudo sobre as espécies ornamentais, principalmente, as que serão utilizadas na ornamentação da escola. Esse estudo pode, por sua vez, auxiliar no cultivo e no direcionamento destas, assim como evitar o plantio das espécies que possam expor risco de intoxicação aos alunos.

As famílias mais frequentes foram, Euphorbiaceae (31,3\%), seguida das famílias Apocynaceae $(18,8 \%)$ e Araceae $(12,5 \%)$. As demais famílias permaneceram com apenas $6,3 \%$ de ocorrência (Figura 3). Conforme Souza et al. (2012), é significante a quantidade de espécies dessas famílias com o potencial de toxicidade em várias partes da planta. Muitas euforbiáceas produzem sementes tóxicas ao homem, normalmente causando acidentes devido a ingestão, principalmente por crianças. Dentro da família Apocynaceae, diversas são tóxicas para o ser humano, portanto, não são totalmente apropriadas para o cultivo em algumas áreas. Na família Araceae, por exemplo, a presença de oxalato de cálcio faz com que as folhas de muitas espécies sejam venenosas, tendo como principal representante a comigo-ninguém-pode.

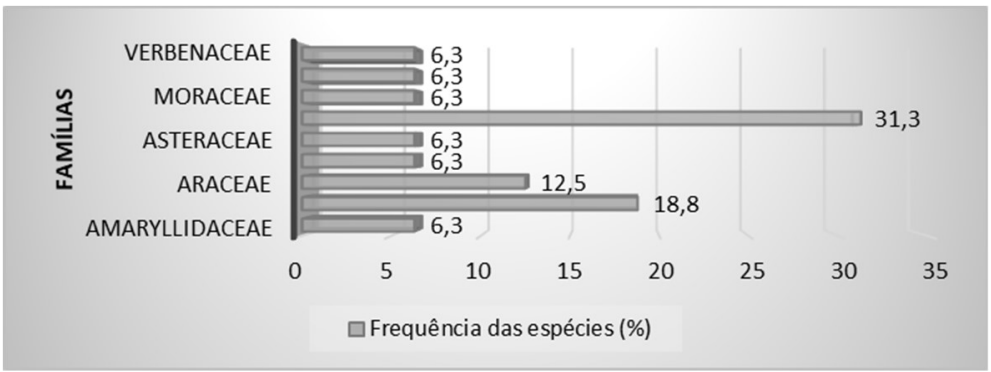

Figura 3: Ocorrência de famílias botânicas encontradas nas escolas do município de Timbiras.

Braga et al. (2017) afirmam que a família Araceae têm importância ornamental, por suas folhas coloridas e atraentes, porém, inúmeras espécies tóxicas pertencem a esta família. Nesse estudo foram encontradas as espécies C. bicolor e D. seguine, popularmente conhecidas na região por pica-pau e comigoniguém-pode, respectivamente.

Nota-se também que, a família Apocynaceae obteve maior ocorrência, porém as espécies J. gossypiifolia, M. esculenta e R. communis L., não são consideradas ornamentais e, portanto, não devem ser cultivadas em ambientes escolares.

\section{Conhecimento dos entrevistados sobre plantas tóxicas}

$\mathrm{Na}$ avaliação dos formulários, obteve-se os seguintes resultados: quando perguntados sobre o conhecimento de plantas tóxicas, $100 \%$ os funcionários e $65 \%$ dos alunos afirmaram que sim. Entre os funcionários, $70 \%$ citaram o nome das plantas que conheciam e 30\% não lembraram ou mesmo não sabiam dizer. Entre os alunos, observou-se que o conhecimento sobre o assunto é muito pouco, pois apenas alguns 
alunos afirmam conhecer. As espécies comigo-ninguém-pode e cansanção foram as mais citadas entre os funcionários e alunos respectivamente (Figura 4).

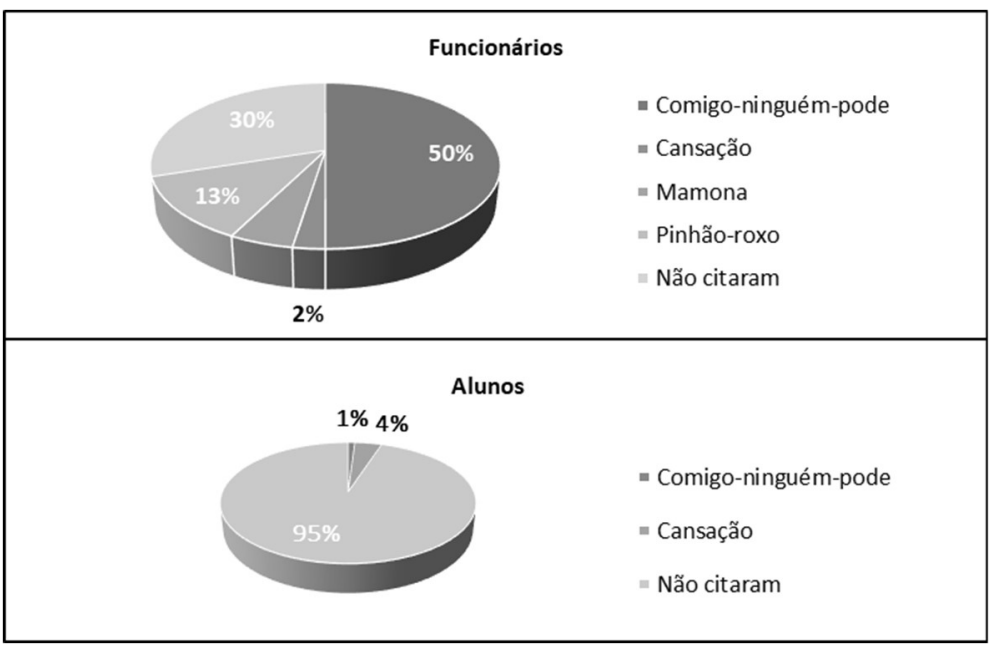

Figura 4: Plantas tóxicas mais conhecidas pelos entrevistados. A. percentual do conhecimento por parte dos funcionários. B. percentual do conhecimento dos alunos.

Alves et al. (2016) realizaram uma pesquisa semelhante nas escolas da cidade de Campina GrandePB e observaram também que era pouco o conhecimento dos alunos a respeito do assunto. No questionamento aplicado por eles, perceberam que nenhum aluno sabia o que seriam plantas ornamentais e apenas alguns dos alunos informaram conhecer o que seriam plantas tóxicas 'plantas venenosas', 'plantas perigosas'. Conforme os autores, apenas duas das oito turmas, as crianças souberam citar pelo menos um exemplo correto de planta tóxica, sendo apenas a urtiga e comigo-ninguém-pode.

No campo das intoxicações por plantas ornamentais, 'comigo-ninguém-pode' (D. seguine) é uma das plantas tóxicas mais conhecidas pela população brasileira e são bastante cultivadas com outras plantas nos jardins das residências e locais públicos. Autores como Vasconcelos et al. (2009), Fook et al. (2014), Mendieta et al. (2014) e Neves et al. (2014) também observaram a popularidade da planta "comigo-ninguém-pode" entre os seus pesquisados.

No que diz respeito a presença de plantas tóxicas nas escolas, apenas $10 \%$ dos funcionários afirmaram que havia; $50 \%$ informaram não haver plantas tóxicas e $40 \%$ não tinha certeza da presença de alguma espécie que fosse tóxica. Quanto a opinião dos alunos, a maioria (96\%) não sabia da existência de plantas tóxicas na escola. Tanto os alunos, quanto os funcionários que haviam dito que a escola possuía planta tóxica, citaram a presença da espécie comigo-ninguém-pode.

Ao serem questionados a respeito do conhecimento sobre os riscos que as plantas tóxicas podem trazer ao ser humano, $45 \%$ dos funcionários afirmaram ter conhecimento. Quanto aos alunos, $41 \%$ apenas informaram que conheciam alguns riscos que elas possuem e 59\% não tem nenhum conhecimento. Tanto os funcionários quanto alunos informaram sintomas como: dormência na língua, inchaço no corpo e nas mãos e dores de barriga, para intoxicação com plantas tóxicas. É importante enfatizar que, ao relacionar funcionários e alunos sobre o nível de informação que estes possuem sobre toxicidade de plantas, percebese uma diferença pequena, de apenas $4 \%$, a respeito do desconhecimento sobre os riscos que elas podem 
provocar por parte dos entrevistados.

Com base nesses dados, percebe-se que o índice de conhecimento sobre a toxicidade das plantas ainda é pequeno e que não somente os alunos devem ser sensibilizados e conscientizados sobre o tema, como também a comunidade escolar em geral. Os casos de intoxicação por planta são em sua maioria acidentais e o fator principal, apontado por vários especialistas, para a ocorrência desses acidentes é o desconhecimento das espécies vegetais tóxicas. Isso é um grande problema, pois as pessoas acabam se automedicando e quando procuram por atendimento médico, acabam omitindo as causas dos sintomas, o que dificulta o diagnóstico e o tratamento adequado. Devido a essas situações, a melhor forma de prevenir a todos é a promoção de atividades educativas com a finalidade de levar conhecimento e a divulgação das espécies tóxicas (VASCONCELOS et al., 2009; GETTER et al., 2011).

Ao avaliar os formulários quando perguntado se houve alguma palestra de conscientização sobre plantas tóxicas nas escolas, $100 \%$ dos entrevistados responderam que não, e quanto a relevância da realização destas para a comunidade escolar, os funcionários responderam que seria de grande importância para aquisição de conhecimento $(42,5 \%)$, conscientização de alunos $(27,5 \%)$ e evitar acidentes $(22,5 \%)$ e apenas 7,5\% não responderam o motivo da importância.

Questionou-se também aos entrevistados se havia algum relato sobre intoxicação na escola e todos responderam não ter presenciado nenhum caso. Porém, é importante ressaltar que um dos funcionários entrevistados relatou um caso de intoxicação por planta em uma residência, em que uma mãe perdeu seus três filhos, pois eles estavam brincando de fazer 'comidinha' e ingeriram a semente da planta chapéu de napoleão (Thevetia peruviana). O mesmo funcionário relatou que seu filho, também, foi intoxicado ao ingerir o fruto do pinhão-roxo em novembro de 2016. O garoto foi rapidamente levado ao hospital, onde foi relatado o caso e tomado as providências corretas. Para Matos et al. (2011) esses acidentes podem ocorrer também, quando frutos são ingeridos ao serem confundidos com alimentos, ou pelo uso de chás inadequados de plantas medicinais. Foi perguntado aos alunos se eles costumavam brincar com as plantas e a maioria deles (73\%) responderam que sim.

Quanto as partes das plantas que eles costumam brincar, em maior frequência estão os frutos e as folhas, com percentual de $28 \%$ e $27 \%$, respectivamente. Dos alunos entrevistados, $25 \%$ afirmaram ter o costume de colocar partes das plantas na boca e $27 \%$ deles não deram nenhuma informação (Figura 5). Conforme Maresch (2015), as crianças são tomadas pela curiosidade de investigar tudo que seja desconhecido e interessante para elas, e com isso elas tendem a colocar muitas coisas na boca ou manipular, o que pode acontecer que uma criança venha a ter o contato com uma planta tóxica. As crianças devem aprender até os seis anos de idade que frutos desconhecidos ou outras partes das plantas não podem ser experimentadas por muitas delas podem conter veneno. E deve-se ensinar às crianças, a partir dos seis anos de idade, sobre o potencial tóxico de específicas plantas e os riscos que elas podem estar correndo (MAIER, 2006). A crianças precisam aprender desde cedo que somente as frutas, flores e frutos, consideradas como alimentos, devem ser colocadas na boca (MARESCH, 2006). 


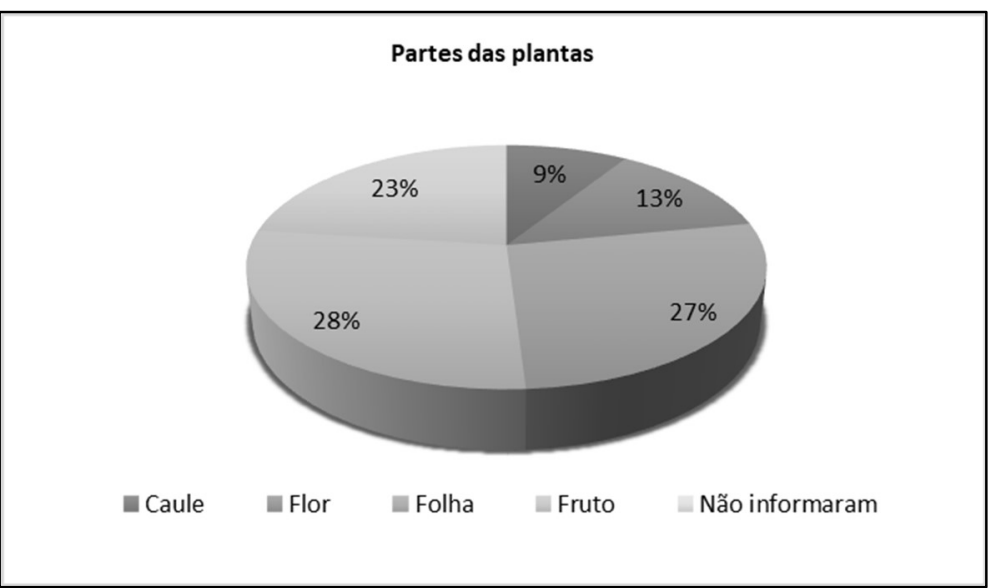

Figura 5: Percentual de alunos que costumam brincar com plantas.

Lima et al. (1995), defendem a ideia de que o conhecimento sobre a parte tóxica e a ação das plantas tóxicas, como também a forma de prevenção poderá minimizar problemas de saúde comuns nestas áreas. Tendo em vista que, as intoxicações por plantas como agente tóxicos, principalmente em crianças, são acidentais e, portanto, podem ser evitadas (VASCONCELOS et al., 2009).

A folha é considerada parte vegetal mais tóxica, seguida pelo látex e caule e os casos de intoxicação mais comuns são por via dérmica (MARTINS et al., 2005). Resultados semelhantes foram encontrados nos trabalhos de Lima et al. (1995), onde verificou-se que a folha e o caule foram as partes vegetais tóxicas mais citadas em todos os vegetais, e a ação tóxica foi por via dérmica, oral e gastrointestinal. As crianças devem aprender nas escolas como lidar com as plantas. Nos jardins de infância, por exemplo, deve-se ensinar que elas podem tocá-las, mas nunca se deve comê-las. Deve-se ensinar também que elas podem comer apenas os frutos, na qual tenham certeza que conheceram em casa ou na sala de aula.

\section{CONCLUSÕES}

Foi identificado a presença de plantas tóxicas na maioria das escolas. As espécies vegetais listadas nas escolas possuem grande potencial de toxicidade, entre elas estão a comigo-ninguém-pode, pica-pau, chapéu-de-napoleão, mamona e o pinhão-roxo. Diante do levantamento dessas espécies, conclui-se que há possibilidades de riscos de intoxicação, principalmente, para as crianças. O conhecimento dos entrevistados sobre o tema é insignificante, necessitando, portanto, a inserção do mesmo não somente no cotidiano dos alunos, mas da comunidade escolar em geral. É necessário promover palestras de conscientização e sensibilização sobre as plantas tóxicas nas escolas, principalmente aos pais de alunos e professores do ensino básico, pois estes são as pessoas responsáveis pela formação das crianças e saberão tomar medidas quanto a prevenção de casos de intoxicação e dar orientação sobre quais plantas não devem ser ingeridas ou tocadas.

Tendo em vista que os casos de intoxicação por plantas são, em sua maioria, acidentais, as intervenções dentro da comunidade escolar, contribuirá bastante tanto para prevenção, quanto para o diagnóstico do problema em casos de intoxicações, uma vez que este, por vezes, não é identificado pelo médico, devido os pacientes omitirem as causas. A divulgação é também considerada uma das formas 
principais para a prevenção de acidentes por plantas, portanto, essa pesquisa é de grande importância para a comunidade escolar, pois tem como foco principal o conhecimento e a divulgação das espécies vegetais tóxicas presentes nas escolas.

\section{REFERÊNCIAS}

AGRA, M. F.; FREITAS, P. F.; BARBOSA-FILHO, J. M.. Synopsis of the plants know as medicinal and poisonous in Northeast of Brazil. Revista Brasileira de Farmacognosia, João Pessoa, v.17, n. 1, p.114-140, 2007. DOI: http://doi.org/10.1590/S0102-695X2007000100021

ALVES, R. B. S.; LIMA, F. A.; COUTINHO, M. S.; MENESES, A. B.; LIMA, E. L. M.; MEIRA, A. M. B.; ARAUJO, C. R. F.; MARIZ, S. R.. Plantas ornamentais $x$ plantas tóxicas: prevenção de acidentes com crianças. Revista Ciência em Extensão, São Paulo, v.12, n.3, p.79-87, 2016.

BIONDI, D.; LEAL, L.; SCHAFFER, M.. Aspectos importantes das plantas ornamentais em escolas públicas estaduais da cidade de Curitiba, PR. Revista Brasileira de Ciências Agrárias, Recife, v.3, n.3, p.267-275, 2008. DOI: http://doi.org/10.5039/agraria.v3i3a325

BOCHNER, R.; FISZON, J. T.; ASSIS, M. A.. Plantas tóxicas ao alcance de crianças: transformando risco em informação. Rio de Janeiro: RIO BOOKS, 2013.

BRAGA, K. C.; GIESE, S. S.; PARRY, S. M.. Levantamento de plantas tóxicas em escolas urbanas de Ensino Fundamental do município de Altamira-Pará. Biota Amazônia, Macapá, v.7, n.2, p.53-58, 2017

CABRAL, C.; PITA, J. R.. Alcalóides: Relevância na farmácia e no medicamento. Coimbra: CEIS 20, 2015.

CABRAL, M. L.. Plantas e civilização: fascinantes histórias da etnobotânica. Rio de Janeiro: Edições de Janeiro, 2016

CAMPIOTO, S. M.; POLETTO, R. S.. Plantas tóxicas ornamentais: riscos que podem ser evitados pela socialização do conhecimento. In: O professor PDE e os desafios da escola pública paranaense: produçao didáticopedagógica. Cornélio Procópio: UENP, 2012.

DUKE, J. A.. Handbook of medicinal herbs. Florida: CRC Press LLC, 1929

FOOK, S. M.; SOARES, Y. C.; ALMEIDA, C. F.; ABRANTES, R. B.; MEIRA, C. M.; FEITOS, I. L.; MARIZ, S. R.. Análise da ocorrência de plantas tóxicas em escolas estaduais no município de Campina Grande (PB) como estratégia na prevenção de intoxicações. Revista Saúde e Ciência Online, Campina Grande, v.3, n.1, p.44-55, 2014.

SINITOX. Sistema Nacional de Informações TóxicoFarmacológicas. Dados de intoxicação. 2019.

GETTER, C. J.; NUNES, J. R.. Ocorrência de intoxicações por plantas tóxicas no Brasil. Engenharia Ambiental, Espírito Santo do Pinhal, v.8, n.1, p.79-100, 2011.

HARAGUCHI, M.. Plantas tóxicas de interesse na pecuária. Instituto Biológico, São Paulo, v.65, n.1-2, p.37-39, 2003.
HESSE, M.. Kinder werden durch Giftpflanzen gefährdet!? Eine kritische Analyse. Biologie Lehren und Lernen.

Zeitschrift für Didaktik der Biologie, v.7, n.1, p.1-19, 2003.

LIMA, R. M.; SANTOS, A. M.; JARDIM, M. A.. Levantamento de plantas tóxicas em duas comunidades caboclas do estuário amazônico. Boletim do Museu Paraense Emílio Goeldi. Série Botânica, Belém, v.11, n.2, p.255-263, 1995.

LOPES, R. K.; RITTER, M. R.; RATES, S. M.. Revisão das atividades biológicas e toxicidade das plantas ornamentais mais utilizadas no Rio Grande do Sul, Brasil. Revista brasileira de Biociências., Porto Alegre, v.7, n.3, p.305-315, 2009.

MAIER, U.. Giftpflanzen: Beschauen, nicht klauen. Düsseldorf: MAGS, 2006.

MARANHÃO. Secretaria de Estado do Meio Ambiente e Recursos Naturais. Plano de ação para prevenção e controle do desmatamento e das queimadas no Estado do Maranhão. Decreto ${ }^{\circ}$ 27.317, de 14 de abril de 2011. São Luís, Maranhão, novembro de 2011.

MARESCH, K.. Giftpflanzen: Ein Begleiter für Eltern und Interessierte. Salzburg: Bildungswerk, 2015.

MARTINS, A. G.; ROSARIO, D. L.; BARROS, M. N.; JARDIM, M A.. Levantamento etnobotânico de plantas medicinais, alimentares e tóxicas da Ilha do Combu, Município de Belém, Estado do Pará, Brasil. Revista Brasileira de Farmácia, Rio de Janeiro, v.86, n.1, p.21-30, 2005.

MATOS, F. J.; LORENZI, H.; SANTOS, L. F.; MATOS, M. E.; SILVA, M. G.; SOUSA, M. P.. Plantas tóxicas: estudo de fitotoxicologia química de plantas brasileiras. São Paulo: Plantarum, 2011.

MENDIETA, M. C.; SOUZA, A. D.; CEOLIN, S.; VARGAS, N. R.; CEOLIN, T.; HECK, R. M.. Plantas tóxicas: importância do conhecimento para a realização da educação em saúde. Revista de Enfermagem UFPE, v.8, n.3, p.680-6, 2014. DOI: http://doi.org/10.5205/reuol.5149-42141-1-SM.0803201424

MUELLER-DOMBOIS, D.; ELLENBERG, H.. Aims and methods of vegetation ecology. New York: J. Wiley, 1974.

NELSON, L. S.; BALICK, M. J.. Handbooks of poisonous and injurios plants. 2 ed. New York: Springer, 2007.

NEVES, G.; LEMES, M.; FAY, L. T.; ANEZ, R. B.; NUNES, J. R. Percepção dos moradores a respeito das espécies tóxicas existentes na praça da Bíblia em Tangará da Serra - MT. Engenharia Ambiental, Espírito Santo do Pinhal, v.11, n.1, p.65-71, 2014. 
OGUNWENMO, K. O.; IDOWU, O. A.; INNOCENT, C.; ESAN, E. B.. Cultivars Codiaeum variegatum (L.) Blume (Euphorbiaceae) show variability in phytochemical and cytological characteristics. African Journal of Biotechnology, Nigéria, v.6, n.20, p.2400-2405, 2007

OLIVEIRA, R. B.; GODOY, S. A.; COSTA, F. B.. Plantas tóxicas: Conhecimento e prevenção de acidentes. Ribeirão Preto: Holos, 2003.

PASSONI, F. D.; OLIVEIRA, R. B.; CHAGAS-PAULA, D. A.; GOBBO-NETO, L.; COSTA, F. B.. Repeated-dose toxicological studies of Tithonia diversifolia (Hemsl.) A. gray and identification of the toxic compounds. Journal of Ethnopharmacology, v.147, n.2, p.389-94, 2013.

PETZOLD, T.. Die wichtigsten für Hunde giftigen Pflanzen. Eltville: Hund.info, 2015.
SOUZA, V. C.; LORENZI, H.. Botânica Sistemática: Guia ilustrativo para identificação das famílias de Fanerógamas nativas e exóticas no Brasil, baseado em APG III. Nova Odessa: Plantarum, 2012

STUART JUNIOR, G. U.. Buddha belly plant. Philippine Alternative medicine, 2016

TEIXEIRA, I. F.. Plantas ornamentais tóxicas: beleza e riscos. São Gabriel, 2011.

TEIXEIRA, J. B.; LIMA, A. A.. Plantas ornamentais tóxicas: prevenção de acidentes. 2011.

VASCONCELOS, J. V.; VIEIRA, E. P.. Plantas tóxicas: conhecer para prevenir. Revista Científica da UFPA, Belém, v.7, p.1$10,2009$.

A CBPC - Companhia Brasileira de Produção Científica (CNPJ: 11.221.422/0001-03) detém os direitos materiais desta publicação. Os direitos referem-se à publicação do trabalho em qualquer parte do mundo, incluindo os direitos às renovações, expansões e disseminações da contribuição, bem como outros direitos subsidiários. Todos os trabalhos publicados eletronicamente poderão posteriormente ser publicados em coletâneas impressas sob coordenação da Sustenere Publishing, da Companhia Brasileira de Produção Científica e seus parceiros autorizados. Os (as) autores (as) preservam os direitos autorais, mas não têm permissão para a publicação da contribuição em outro meio, impresso ou digital, em português ou em tradução. 